\title{
Synthesis and Characterization of Amide Stationary Phases for the Determination of Sulfonamides by Sequential Injection Chromatography
}

\author{
Gabriela Islas, Jose A. Rodríguez, Julian Cruz-Borbolla, José M. Vásquez-Pérez \\ \& Enrique Barrado
}

To cite this article: Gabriela Islas, Jose A. Rodríguez, Julian Cruz-Borbolla, José M. VásquezPérez \& Enrique Barrado (2016) Synthesis and Characterization of Amide Stationary Phases for the Determination of Sulfonamides by Sequential Injection Chromatography, Analytical Letters, 49:5, 676-689, DOI: $10.1080 / 00032719.2015 .1045589$

To link to this article: http://dx.doi.org/10.1080/00032719.2015.1045589

Accepted author version posted online: 08 Jun 2015.

Submit your article to this journal $\sqsubset$

凹ll Article views: 27

a

View related articles

View Crossmark data \lceil 


\title{
Synthesis and Characterization of Amide Stationary Phases for the Determination of Sulfonamides by Sequential Injection Chromatography
}

\author{
Gabriela Islas ${ }^{\mathrm{a}}$, Jose A. Rodríguez ${ }^{\mathrm{a}}$, Julian Cruz-Borbolla ${ }^{\mathrm{a}}$, José M. Vásquez-Pérez ${ }^{\mathrm{a}, \mathrm{b}}$, and \\ Enrique Barradoc

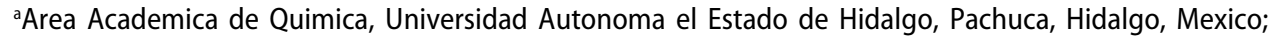

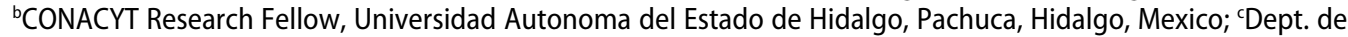 \\ Química Analítica, Facultad de Ciencias, Universidad de Valladolid, Valladolid, Spain
}

\begin{abstract}
The synthesis of amide (butyl, cyclohexyl, and phenyl) modified silica and the use as stationary phases in sequential injection chromatography are described. The system was tested on the isocratic separation of seven sulfonamides (sulfachloropyridazine, sulfadimethoxine, sulfamethazine, sulfamethoxazole, sulfamethoxypyridazine, sulfaquinoxaline, and sulfathiazole) using each stationary phase with mobile phases composed of acetonitrile/water at a flow rate of $0.45 \mathrm{~mL} \mathrm{~min}{ }^{-1}$. A mixed mode retention mechanism of sulfonamides in the stationary phases was obtained, including dipole-dipole, $\pi-\pi$, and hydrogen bonding interactions. The most appropriate phase for the separation of sulfonamides was phenylamide. The chromatographic behavior was confirmed using density functional theory of the interaction between sulfamethoxazole and the stationary phases.
\end{abstract}

\section{ARTICLE HISTORY}

Received 5 December 2014

Accepted 16 April 2015

\section{KEYWORDS}

Density functional theory; sequential injection chromatography; solid phase interaction; sulfonamides

\section{Introduction}

In recent decades, new analytical methodologies have developed to obtain precise, accurate, and economic results in a short period of time. Flow methods are generally fast, robust, and flexible. These methods are used to manipulate, mix, and transport samples and reagents for the development of reactions using a microscale approach (Idris 2010, 2014). Their extreme versatility distinguishes them from other analytical techniques because they provide fast, accurate, and precise results. Sequential injection chromatography (SIC) is a well-established technique that integrates a short separation column into a sequential injection analysis (SIA) flow system (Chocholouš, Solich, and Šatínský 2007). SIC has already been consolidated as a good alternative to high performance liquid chromatography (HPLC) for the analysis of mixtures at low-pressures (Chocholouš, Solich, and Šatínský 2007; González-San Miguel et al. 2009; Idris 2010). The use of the 8-port selection valve allows the combination of a series of reagents or samples. The low pressure syringe pump allows the modification of the speed and the direction of the flow.

CONTACT Jose A. Rodríguez jara.uaeh@gmail.com; josear@uaeh.edu.mx E Area Academica de Quimica, Universidad Autonoma el Estado de Hidalgo, Carr. Pachuca Tulancingo km 4.5, Pachuca, Hidalgo 42076, Mexico.

Color versions of one or more of the figures in the article can be found online at http://www.tandfonline.com/lanl.

This paper is part of a special issue on Automated Flow Injection Based Analytical Techniques organized by Dr. Paraskevas Tzanavaras of Aristotelian University of Thessaloniki. 
In general, monolithic columns are used as stationary phases because of their low resistance to flow due to the high porosity of monolithic materials. Silica $\mathrm{C}_{18}$ (Chocholouš et al. 2011, 2013), polymer-based (polyacrylamide gels), synthetic organic materials (acrylate resins), natural polymers (cellulose), and preparative columns have been used for SIC (Šatínský et al. 2003; Guiochon 2007; Jangbai et al. 2012). The SIC separations are performed using sample volumes and flow rates between 10 and $200 \mu \mathrm{L}$ and from 0.5 to $2.4 \mathrm{~mL} \mathrm{~min}^{-1}$, respectively, and the available pressures of the relief valve are currently 250-500 psi (Idris 2014). However, the low pressures supported by the SIC system limit their application. The high porosity due to the presence of macropores allows the use of higher flow rates, thus reducing the analysis time. The mesopores form a fine porous structure and provide a larger surface active area than used in high efficiency separations (Minakuchi et al. 1997; Gritti and Guiochon 2004). On the other hand, packed columns have the advantage of using stationary phases with different functional groups (Unger, Skudas, and Schulte 2008).

SIC methodologies have been developed for the analysis of pharmaceutical formulations, urine, blood serum, water, and food. The most commonly stationary phase employs $\mathrm{C}_{18}$ monolithic columns $(25 \times 4.6 \mathrm{~mm})$ (Fernández et al. 2008; Infante, de Prá Urio, and Masini 2011; Koblová et al. 2011). The use of fused-core-packed columns of higher dimensions $(30 \times 4.6 \mathrm{~mm}$, particle size $2.7 \mu \mathrm{m})$ has also been studied with: amide, $\mathrm{C}_{18}$, and phenylhexyl for the determination of phenolic acids using a valve which supports pressures up to 1000 psi (Chocholouš et al. 2013). The use of smaller particles $(2 \mu \mathrm{m})$ has been described forming thin layers on the inner wall of minicolumns using silica-coated magnetite of different polarity (Ibarra et al. 2013).

Separations with stationary phases that contain different functional groups such as amide, amine, ester, and urea in which there may be hydrogen bonding and intermolecular interactions has been proposed for applications in hydrophilic interaction liquid chromatography (Kirkland 2004; Snyder, Dolan, and Carr 2004; Rimmer and Sander 2009). These stationary phases, with mixed mode interactions, have been applied to the analysis of polar compounds such as carbohydrates (Churms 1996), peptides (Cai et al. 2012), proteins (Guo, Li, and Frey 2014), and catecholamines (Aturki et al. 2011).

The use of modified silica with aliphatic and aromatic amides may be an alternative to improve the retention of low molecular weight molecules. Currently, there is a minimal amount of information regarding the use of amide modified silica stationary phases for separation of sulfonamides by SIC. Therefore, the present work evaluates the characteristics of retention on stationary phases that contain butyl, cyclohexyl, and phenyl amides in SIC systems. The functional groups promote additional interactions between the stationary phase and the analyte which improves chromatographic behavior. Sulfonamides are widely used for treatment of bacterial infections in humans and animals. Hence, the development of analytical methods useful in environmental (Seifrtová et al. 2009; García-Galán, Díaz-Cruz, and Barceló 2013) and food (Kishida and Furusawa 2001; Ibarra et al. 2014) samples is required.

\section{Experimental}

\section{Reagents and solutions}

Silica gel $60\left(40-60 \mu \mathrm{m}\right.$, surface area $\left.460-520 \mathrm{~m}^{2} \mathrm{~g}^{-1}\right)$ was purchased from Merck KGaA (Darmstadt, Germany). 3-(Aminopropyl) trimetoxysilane (99\%), triethylamine (99\%), 
methyl acrylate (99\%), butylamine (99.5\%), cyclohexylamine (99\%), and Aniline (99\%), were obtained from Sigma (St. Louis, MO, USA). HPLC-grade acetonitrile, methanol, anhydrous toluene, and ethanol were from J.T. Baker (Phillipsburg, NJ, USA) and water from a Milli-Q system (Millipore, Bedford. M.A, USA) was used throughout the experiments.

Sulfachloropyridazine (99.4\%), sulfadimethoxine (99.8\%), sulfamethazine $(99.8 \%)$, sulfamethoxazole $(99 \%)$, sulfamethoxypyridazine $(99.2 \%)$, sulfaquinoxaline $(99.1 \%)$, and sulfathiazole $(99.9 \%$ ) were obtained from Sigma (Steinheim, Germany). The standard solutions were prepared in acetonitrile and stored at $4^{\circ} \mathrm{C}$ and renewed weekly. Working standard solutions with the sulfonamides were daily prepared in acetonitrile-water $(1: 1 \mathrm{v} / \mathrm{v})$. A $20 \mathrm{mg} \mathrm{L}^{-1}$ solution of each sulfonamide was used for optimization of the separation and evaluation of the columns. The chromatography separation was evaluated under isocratic conditions.

\section{Synthesis of stationary phases}

Silica gel $(3.0 \mathrm{~g})$ was suspended in $40 \mathrm{ml}$ of $\mathrm{HCl}\left(3 \mathrm{~mol} \mathrm{~L}^{-1}\right)$, refluxed for $8 \mathrm{~h}$, filtered, and washed with ultrapure water until a neutral $\mathrm{pH}$ value was obtained. The solid was filtered and allowed to dry at $120^{\circ} \mathrm{C}$ overnight ( $\mathrm{Li}$ et al. 2013).

Activated silica $(3.0 \mathrm{~g})$ was mixed with $30 \mathrm{ml}$ of anhydrous toluene, $0.5 \mathrm{ml}$ of trimethylamine, and $3 \mathrm{ml}$ of 3-(Aminopropyl) trimetoxysilane and refluxed for $24 \mathrm{~h}$. The 3(Aminopropyl) trimetoxysilane-bonded silica was filtered and thoroughly washed with toluene followed by ethanol $(3 \times 10 \mathrm{~mL})$ and dried at $60^{\circ} \mathrm{C}$ for $12 \mathrm{~h}$. The dried solid was immersed in $60 \mathrm{~mL}$ methyl acrylate/methanol $(1: 1, \mathrm{v} / \mathrm{v})$ and stirred under nitrogen at $50^{\circ} \mathrm{C}$ for $2 \mathrm{~h}$. The product was filtered and washed with methanol to obtain ester group modified silica (Xu et al. 2013).

The solid phase with the ester group was reacted with $30 \mathrm{~mL}$ primary amines in methanol solution $(1: 1, \mathrm{v} / \mathrm{v})$ and stirred at $50^{\circ} \mathrm{C}$ for $8 \mathrm{~h}$. The products were filtered and washed with methanol to obtain different amide groups with aliphatic chains. All the derived products SP-1 (aniline), SP-2 (butylamine), and SP-3 (cyclohexylamine), were washed and dried $\left(60^{\circ} \mathrm{C}, 8 \mathrm{~h}\right)$.

\section{Sample preparation}

The methodology was tested in the analysis of urine samples. $1.0 \mathrm{~mL}$ of urine, containing 10 and $30 \mathrm{mg} \mathrm{L}^{-1}$ of sulfamethoxazole, was mixed with $2.0 \mathrm{~mL}$ of acetonitrile in a polypropylene centrifuge tubes $(10 \mathrm{ml})$. The mixture was vortex mixed for $5 \mathrm{~min}$ (Barnstead/ Thermolyne, IA, USA). The mixture was centrifuged for $15 \mathrm{~min}$ at $3200 \mathrm{rpm}$, and the supernatant was analyzed by the SIC system (Chen, $\mathrm{Wu}$, and $\mathrm{Wu} 2015$ )

\section{Equipment}

The SIC system (Figure 1) consisted of a programmable speed burette multisyringe $(10 \mathrm{~mL}$; MicroBu 2030, Crison) that was used to aspire and dispense the reagents solutions. An eight-way selection valve (Pump 2060, Crison) connected to a high density polypropylene mini-column of $50 \times 4.5 \mathrm{~mm}$ was packed with the synthesized solid phases: SP-1, SP-2, and 


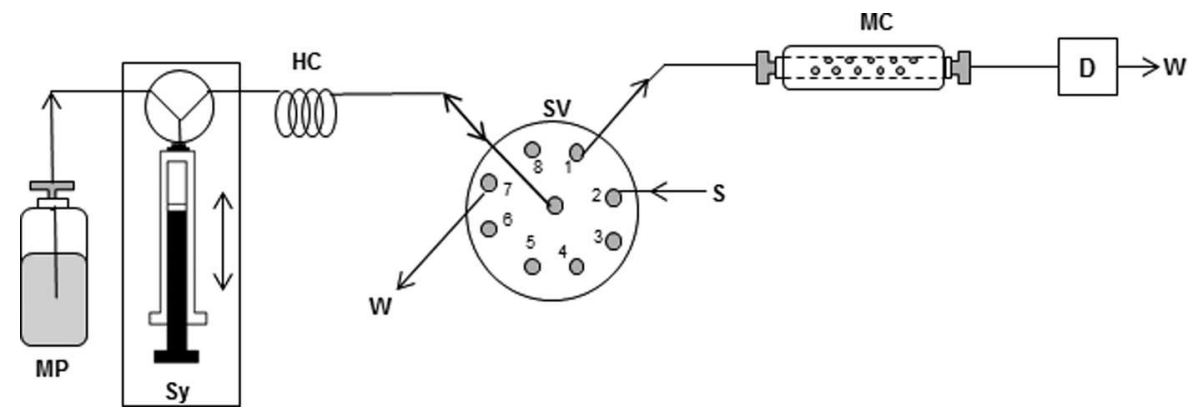

Figure 1. Schematic of SIC for determination of sulfonamides: MP, mobile phase; Sy, Syringe Pump; $\mathrm{HC}$, holding coil; SV, selection valve; S, sample; MC, mini-column; D, detector; and W, waste.

SP-3. The mini-column was slurry-packed with the different stationary phases. The extremities on the column were fitted with glass microfiber filters with a pore size of $2.7 \mu \mathrm{m}$ (Whatman, Grade GF/D). $2.0 \mathrm{~mL}$ of a modified silica suspension in acetonitrile $\left(25 \mathrm{mg} \mathrm{mL}^{-1}\right)$ were suctioned using a vacuum pump. The column was conditioned by passing acetonitrile:water $(1: 1, \mathrm{v} / \mathrm{v})$ through the column at a flow rate of $0.3 \mathrm{~mL} \mathrm{~min}{ }^{-1}$ over $30 \mathrm{~min}$. This home-made mini-column supported a system pressure of $100 \mathrm{psi}$.

The column was connected to a ultraviolet-visible spectrophotometer (Lambda 40, Perking-Elmer), coupled to a quartz cell of $18 \mu \mathrm{L}$ internal volume and $1.0 \mathrm{~cm}$ path-length 178.712QS flow-through detector cell Hellma (Muellheim/Baden, Germany). Omnifit polytetrafluoroethylene tubing $(0.8 \mathrm{~mm}$ i.d.) connected the components of the flow system. The instrument devices were controlled by Autoanalysis 5.0 software (Sciware systems SL, Spain).

Infrared characterization of the synthesized solid phases were performed using a PerkinElmer Fourier Transform Infrared Spectrophotometer model IRDM. The samples were analyzed as $\mathrm{KBr}(1 \%)$ sample pellets. The morphological analysis of the solid phase was performed using a JEOL JSM-820 scanning electron microscope (SEM; JEOL Inc., Peabody, MA, USA).

\section{Analytical cycle}

Initially, the solid phase was conditioned by passing a mobile phase composed of acetonitrile/water (1:1) through the column at a flow rate of $0.3 \mathrm{~mL} \mathrm{~min}{ }^{-1}$ during $30 \mathrm{~min}$. The SIC system began with an aspiration of a $40 \mu \mathrm{L}$ aliquot of sample (port 2) to the holding coil (HC) , and transport towards the mini-column (port 1), at a flow rate of $0.45 \mathrm{~mL} \mathrm{~min}{ }^{-1}$ for $20 \mathrm{~min}$, while the signal was recorded at $270 \mathrm{~nm}$.

\section{Density functional theory}

A theoretical study was conducted to evaluate interactions between the synthesized stationary phases (aniline, butylamine, and cyclohexylamine) with sulfamethoxazole as target molecule. All calculations were performed using the dftb + (Aradi, Hourahine, and Frauenheim 2007) and deMon2k (Geudtner et al. 2012) computational chemistry packages. Density-functional tight-binding was used to find the most stable 
conformations of the functionalized silica molecules using the simulated annealing technique starting from random conformations for the three types of molecules. The forces for the annealing of the functionalized silica fragments were calculated with the self-consistent-charge density-functional tight-binding (Elstner et al. 1988) theory using the MATSCI and 3ob sets of Slater-Köster parameters (Gaus, Goez, and Elstner 2013; Gaus et al. 2014). A linear cooling schedule from 1200 to $10 \mathrm{~K}$ was applied using a Nose-Hoover chained thermostat. Local optimization of the annealed geometries with the auxiliary density functional theory (Köster, Reveles, and del Campo 2004) was performed using the deMon2k package in order to find the most stable conformation of each pair. The sulfamethoxazole molecule was also optimized with the deMon $2 \mathrm{k}$ package starting from the crystallographic geometry reported in the Crystallography Open Database (Crystallography.net 2014). Molecular dynamics simulations of the optimized sulfamethoxazole molecule and optimized silica fragments were performed at $300 \mathrm{~K}$ at the density-functional tight-binding level in order to find the most favorable orientations. The five most stable orientations were selected from each trajectory and optimized with the deMon2k program at the generalized gradient approximation level including dispersion corrections. The adsorption energies were calculated as the difference between the energy of the interacting molecules and the sum of the isolated silica and sulfamethoxazole energies.

\section{Results and discussion}

\section{Preparation and characterization of the solid phase}

One of the most important characteristics of the prepared stationary phases with the synthesized solids is the retention mechanism of the analytes through hydrogen bonding, electrostatic interactions, and hydrophobic interactions. Three different stationary phases were synthesized using different amides with aliphatic chains that were evaluated for sulfonamide retention. Infrared spectra of the compounds were obtained in order to identify the presence of the functional groups in the modified silica gel.

Figure 2 shows the infrared spectra of the modified and unmodified silica. The spectrum for the SP-0 sample (unmodified silica) contained a stretching band at $1300-1000 \mathrm{~cm}^{-1}$ assigned to the siloxane group ( $\mathrm{Si}-\mathrm{O}-\mathrm{Si}$ ) and a stretching band at $3453 \mathrm{~cm}^{-1}$ attributed to the vibration of the silanol group (Si-OH). A bending band at $1645 \mathrm{~cm}^{-1}$ was attributed to the $\mathrm{H}_{2} \mathrm{O}$ contained in the silica gel. The spectra of SP-1, SP-2, and SP-3 samples showed a band attributed to the flexion of $\mathrm{N}-\mathrm{H} 1650-1515 \mathrm{~cm}^{-1}$ and a band corresponding to the vibration of $\mathrm{C}=\mathrm{O}$ at $1695-1650 \mathrm{~cm}^{-1}$ characteristic of the amide group. Additionally, the SP-1 shows two bands above $3020 \mathrm{~cm}^{-1}$ and $3600 \mathrm{~cm}^{-1}$ corresponding to the $=\mathrm{C}-\mathrm{H}$ vibrations of the phenyl group. The infrared spectra indicate the presence of the desired amides in the solids.

The amide groups may interact among themselves via hydrogen bonding and interact with the mobile phases components through polar interactions. The aliphatic chain presented hydrophobic characteristics and dipole-dipole interactions while the phenyl group may interact through a $\pi-\pi$ stacking mechanism (Croes et al. 2005).

The morphology of the solid phases was studied by scanning electron microscopy (SEM). As shown in Figure 3, an amorphous solid was obtained. The particle size for 


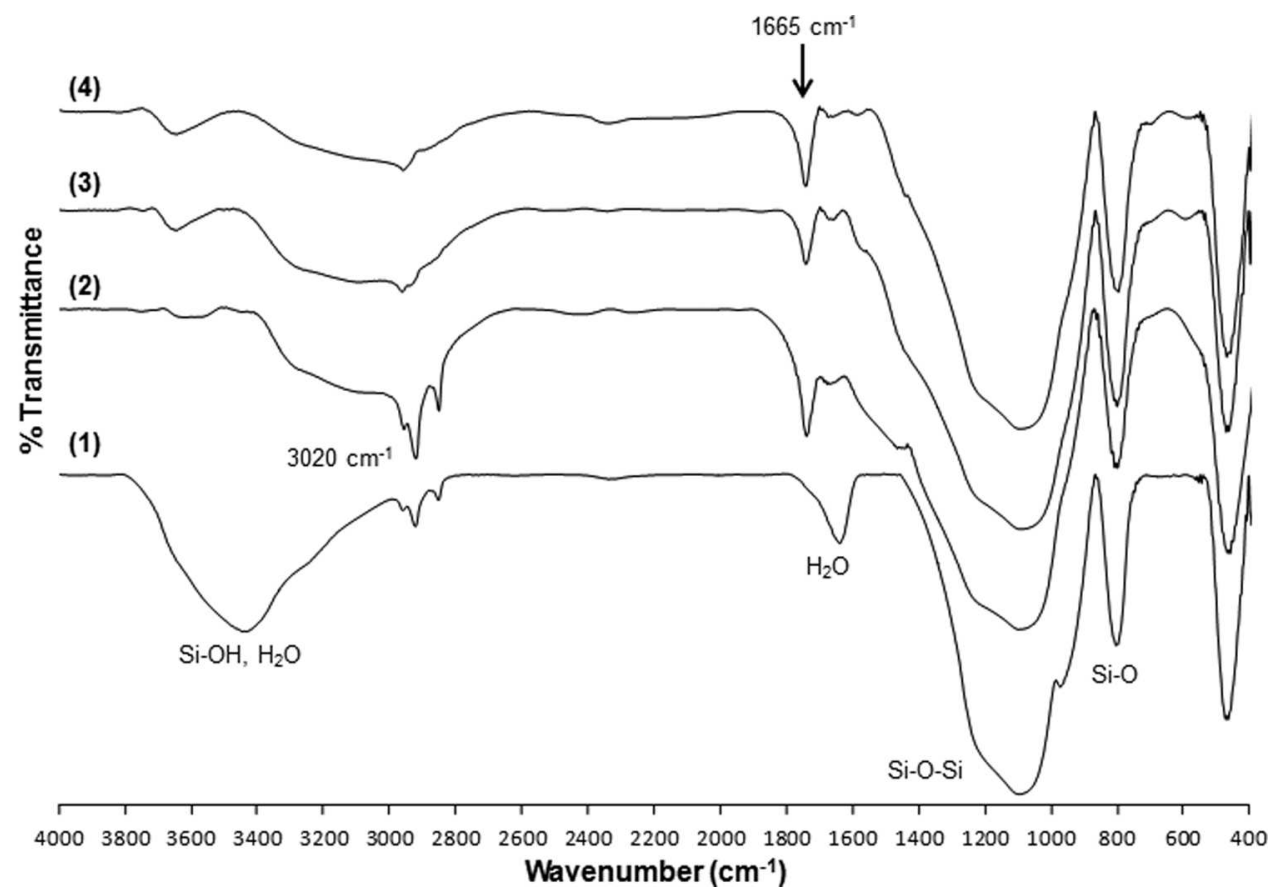

Figure 2. Infrared spectra of the modified silica materials: (1) SP-0 Activated silica; (2) SP-1 phenylamide; (3) SP-2 butylamide, and (4) SP-3 cyclohexylamide.

the stationary phases was higher than $10 \mu \mathrm{m}$ in all cases. The synthesized solids possessed suitable characteristics for their use in SIC systems with low pressures.

\section{Chromatography studies}

Separation of highly polar and basic compounds is an analytical challenge on traditional hydrophobic stationary phases (McCalley 2010). The development of a new analytical method requires the evaluation of the effects of variables for the system. In order to
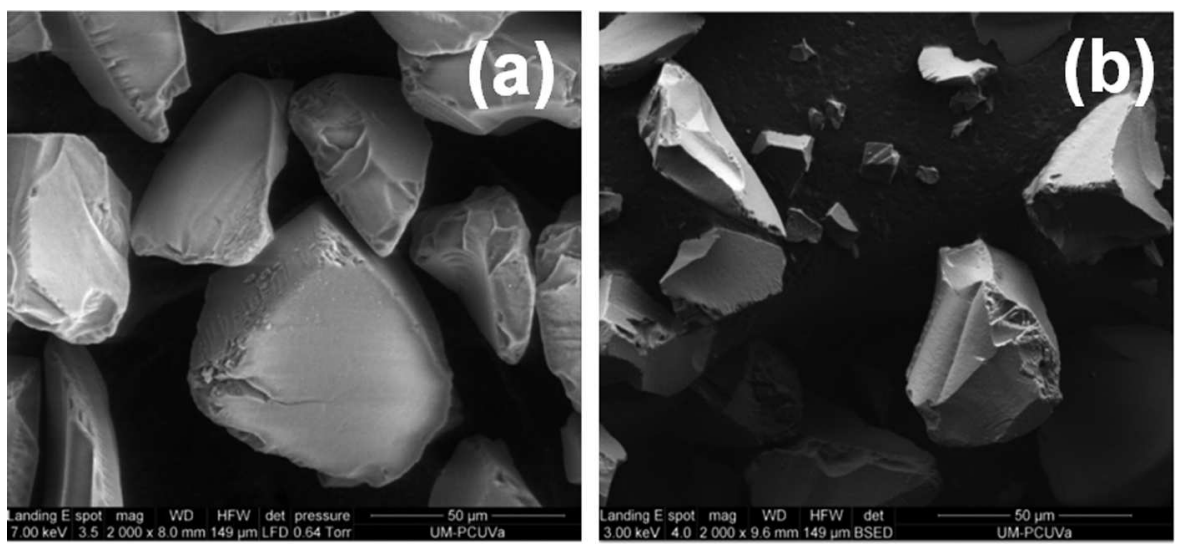

Figure 3. Micrographs for the solid phases: (a) SP-0 and (b) SP-1. 
investigate its hydrophobic-hydrophilic retention properties, acetonitrile/water was used as mobile phase. The parameters evaluated were the composition of the mobile phase and stationary phases.

The mobile phase composition was studied to obtain optimal conditions for the separation of the seven sulfonamides. In this study, four different mobile phase compositions were tested: acetonitrile: water (90:10, 70:30, 50:50, 30:70 v/v) using the different mixed solid phases synthesized. The percentage of acetonitrile in the mobile phase significantly affected the resolution of the sulfonamides, whose respective partition coefficient octanol-water $(\log$ P) are shown in Table 1 (Gonzales and Usher 2009; Dioumaeva 2013). In all cases, decreases in acetonitrile concentration improved the resolution of all stationary phases. However, when the separation was performed using a ratio less than 50:50, the retention times were higher than $20 \mathrm{~min}$. According to the results, the use of this relationship imparts a compromise between a decrease of the organic solvent consumption and the resolution of the signals.

Figure 4 shows the chromatograms obtained in the separation of sulfonamides with the three solid phases. The chromatograms obtained in all cases show an effective separation of the analytes. However, the partition of each sulfonamide varied according to the interaction with the functional groups in the stationary phases. Figure 4a shows the separation performed with phenylamide, where the main interactions are $\pi-\pi$ stacking and hydrogen bonds. On the other hand, Figure $4 \mathrm{~b}$ shows the butylamide chromatogram; retention involves hydrophobic interaction with the butyl group, whereas cyclohexylamide (Figure 4c) contributed through a dipole-dipole interaction.

The chromatographic behaviors were calculated from retention time, retention factor $\mathrm{K}^{\prime}$, peak resolution, peak symmetry, number of theoretical plates and height equivalent to a theoretical plate (HETP) as recommended by the Food and Drug Administration, U.S. (1994). The chromatographic parameters for the columns are shown in Table 2. The successful separation of the sulfonamides is not only attributed to the best physical properties of the columns (i.e., shorter diffusion path and partial porosity) but to the different structures in the stationary phases that enabled differential interactions with the analytes (Croes et al. 2005; Zhang et al. 2014).

The SP-1 presents a higher number of theoretical plates attributed to the efficiency of the column in the separation, but its resolution between the peaks decreases as the retention time increases. This loss of resolution affects the selectivity (separation factor), the efficiency, and the retention (capacity factor). Unlike SP-2 and SP-3, which presented an adequate resolution $>1.5$, SP-2 presents the characteristics ideal for chromatographic separation of sulfonamides. According to (Zhao et al. 2007), the log P vs log K' presents a linear relation in reversed phase separation based on hydrophobic interactions. The graphic

Table 1. Octanol-water partition coefficient $(\log P)$ for sulfonamides.

\begin{tabular}{lcc}
\hline Name & $\log \mathrm{P}$ & Reference \\
\hline Sulfaquinoxaline & 1.70 & Dioumaeva (2013) \\
Sulfacloropyridazine & 1.36 & \\
Sulfadimethoxine & 1.56 & Gonzales and Usher (2009) \\
Sulfamethazine & 0.43 & \\
Sulfamethoxazole & 1.58 & \\
Sulfamethoxypyridazine & 1.01 & \\
Sulfathiazole & 0.35 & \\
\hline
\end{tabular}




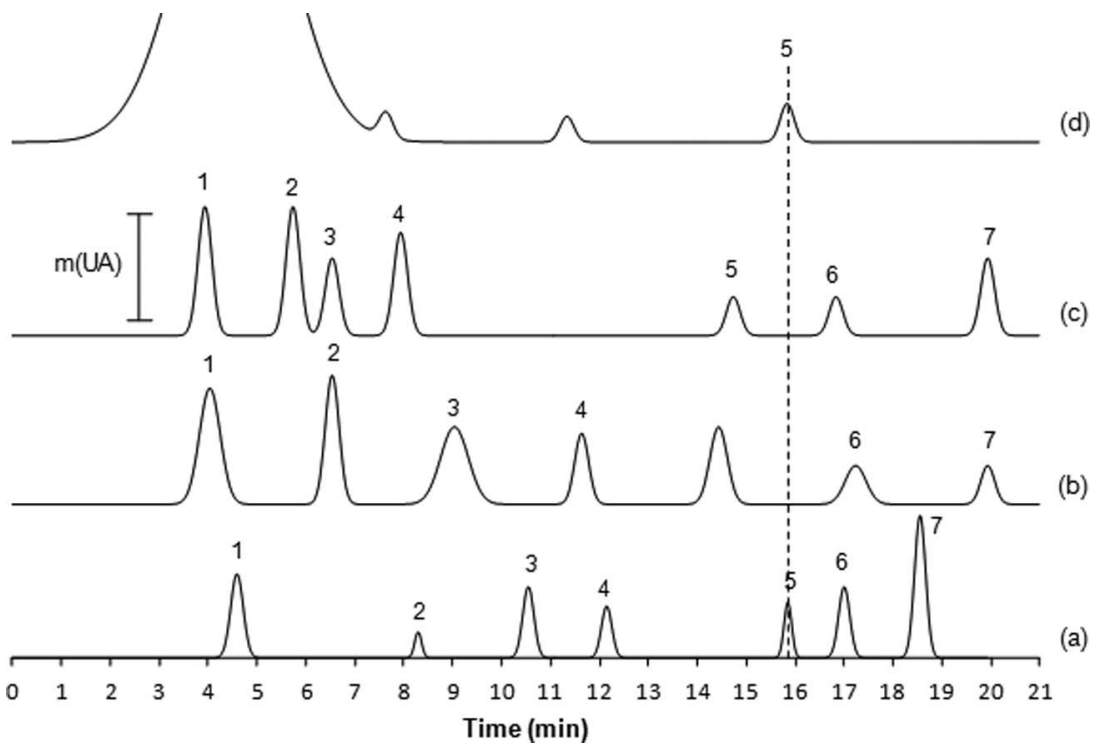

Figure 4. Chromatograms obtained from the analysis of sulfonamides by SIC with a mobile phase of acetonitrile:water 50:50, $20 \mathrm{mg} \mathrm{L}^{-1}$ standard, injection volume of $40 \mu \mathrm{L}$, flow rate of $0.45 \mathrm{ml} \mathrm{min}^{-1}$, and ultraviolet detection at $270 \mathrm{~nm}$. Synthesized solid phase: (a) SP-1, Phenylamide; (b) SP-2, Butylamide; (c) SP-3, Cyclohexylaminde; (d) urine sample at a concentration of $15.4 \mathrm{mg} \mathrm{L}^{-1}$ (sulfamethoxazole), as stationary phase using phenylamide. Peaks: (1) sulfathiazole; (2) sulfamethazine; (3) sulfamethoxypyridazine; (4) sulfacloropyridazine; (5) sulfamethoxazole; (6) sulfadimethoxine; and (7) sulfaquinoxaline.

obtained using the amide stationary phases, does not show this tendency, which confirms the presence mixed mode interactions during the separation.

Table 3 shows various liquid chromatography techniques used for separation of sulfonamides. The most common strategy is based on reverse phase mode in HPLC with

Table 2. Chromatographic parameters of SIC process of the separation the sulfonamides: (1) sulfathiazole; (2) sulfamethazine; (3) sulfamethoxypyridazine; (4) sulfacloropyridazine; (5) sulfamethoxazole; (6) sulfadimethoxine; and (7) sulfaquinoxaline.

\begin{tabular}{llllllllc}
\hline & \multicolumn{1}{c}{ Stationary phase } & 1 & 2 & 3 & 4 & 5 & 6 & 7 \\
\hline Retention time & SP-1: Phenylamide & 4.5 & 8.3 & 10.6 & 12.2 & 15.9 & 17.2 & 18.6 \\
& SP-2: Butylamide & 3.9 & 6.5 & 9.0 & 11.6 & 14.5 & 17.2 & 20.0 \\
& SP-3: Cyclohexylamide & 4.0 & 5.8 & 6.6 & 8.0 & 14.8 & 16.9 & 20.0 \\
Retention factor $K^{\prime}$ & SP-1: Phenylamide & 1.02 & 2.60 & 3.60 & 4.30 & 5.90 & 6.40 & 7.10 \\
& SP-2: Butylamide & 1.2 & 2.5 & 3.8 & 5.2 & 6.6 & 8.1 & 9.5 \\
& SP-3: Cyclohexylamide & 1.5 & 2.6 & 3.1 & 4.0 & 8.2 & 9.5 & 11.5 \\
Peak resolution $>1.5$ & SP-1: Phenylamide & 6.1 & 4.2 & 2.4 & 6.1 & 1.8 & 2.3 & - \\
(Limit) & SP-2: Butylamide & 2.4 & 2.4 & 2.1 & 2.4 & 2.0 & 2.1 & - \\
& SP-3: Cyclohexylamide & 2.0 & 0.9 & 1.7 & 7.8 & 2.6 & 3.8 & - \\
Peak symmetry 0.8-1.5 & SP-1: Phenylamide & 0.96 & 1.05 & 0.99 & 1.08 & 0.93 & 0.96 & 1.04 \\
(Limit) & SP-2: Butylamide & 1.01 & 0.99 & 0.97 & 1.01 & 0.98 & 0.98 & 0.96 \\
& SP-3: Cyclohexylamide & 1.03 & 0.97 & 1.01 & 0.98 & 0.94 & 0.96 & 0.98 \\
Number of theoretical plates & SP-1: Phenylamide & 571 & 6143 & 3740 & 5590 & 12785 & 10276 & 10443 \\
& SP-2: Butylamide & 177 & 861 & 965 & 1261 & 2876 & 1524 & 10741 \\
& SP-3: Cyclohexylamide & 288 & 694 & 1039 & 1299 & 4808 & 7643 & 8223 \\
Height equivalent to a & SP-1: Phenylamide & 87.5 & 8.1 & 13.4 & 8.9 & 3.9 & 4.8 & 4.7 \\
theoretical plate $(\mu \mathrm{m})$ & SP-2: Butylamide & 281.7 & 58.0 & 51.8 & 39.6 & 17.4 & 32.8 & 4.6 \\
& SP-3: Cyclohexylamide & 173.2 & 72.0 & 48.1 & 38.4 & 10.4 & 6.5 & 6.1 \\
\hline
\end{tabular}

Resolution: $1 / 2 ; 2 / 3 ; 3 / 4 ; 4 / 5 ; 5 / 6 ; 6 / 7$. 


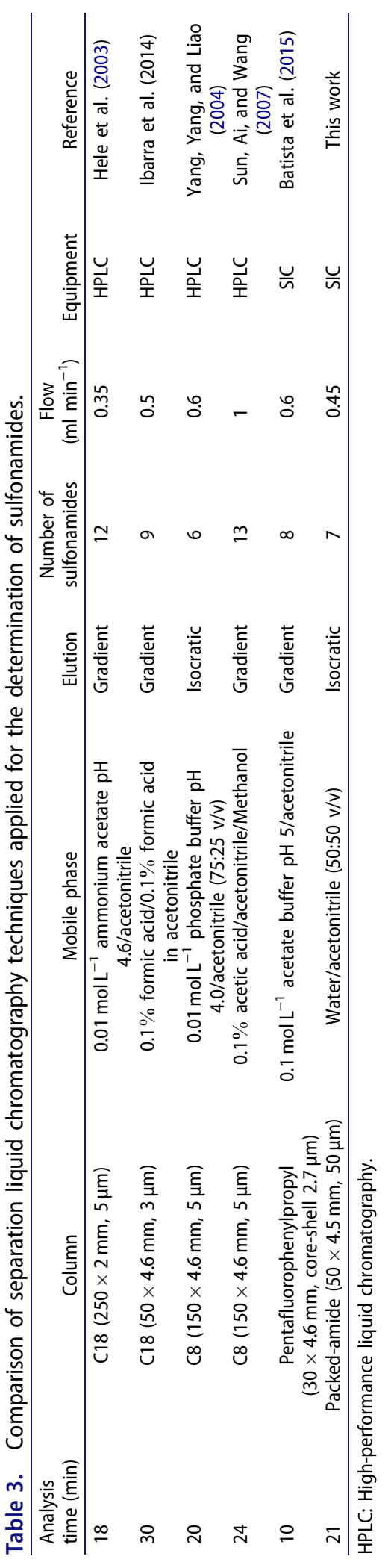


octadecyl- $\left(\mathrm{C}_{18}\right)$ and octyl- $\left(\mathrm{C}_{8}\right)$ stationary phases with particles sizes less than $5 \mu \mathrm{m}$. The mobile phases used were composed by acetonitrile and acid aqueous phases and the separation were generally performed using gradients. The analysis time of sulfonamides was similar than the values obtained using gradient elution modes. In SIC, the use of a fused-core stationary phase of pentafluorophenylpropyl has been described in combination with gradient elution with a mobile phase similar to the approach for HPLC.

The separation using SIC with amide stationary phases allows a lower resolution compared with separation using lower particles sizes. However, this methodology is a competitive strategy that can be used to analyze complex samples such as urine which usually contains one or two sulfonamides. In order to corroborate the usability, a urine sample was analyzed by SIC using the phenylamide stationary phase because it had the highest number of theoretical plates. The Figure 4(d) shows the chromatogram obtained from the analysis of a real sample. A concentration of $15.4 \mathrm{mg} \mathrm{L}^{-1}$ was found in the sample. The average recoveries obtained from the analysis of the fortified sample with sulfamethoxazole with 10 and $30 \mathrm{mg} \mathrm{L}^{-1}$ were $97.3 \pm 2.56 \%$ and $101 \pm 3.46 \%$, respectively. The precision of the methodology, expressed as relative standard deviation (RSD, $n=3$ ), was less than $5 \%$ in all cases.

\section{Molecular modeling}

In order to evaluate the possible interactions in the synthesized stationary phases, a theoretical study was conducted using sulfamethoxazole as the target molecule. Figure 5 shows the most stable orientation for each substituent. The corresponding adsorption energies are reported in Table 4. The average adsorption energy of the five most stable conformers is also shown in the last column of Table 4 . Figure $5(\mathrm{a}-\mathrm{c})$ show that hydrogen bonds are formed between the sulfamethoxazole molecule and the substituent of the silica fragments. In the case of butylamide, at least two hydrogen bonds are formed as shown in Figure 5(a), and for cyclohexylamide and phenylamide, at least one hydrogen bond is formed as shown

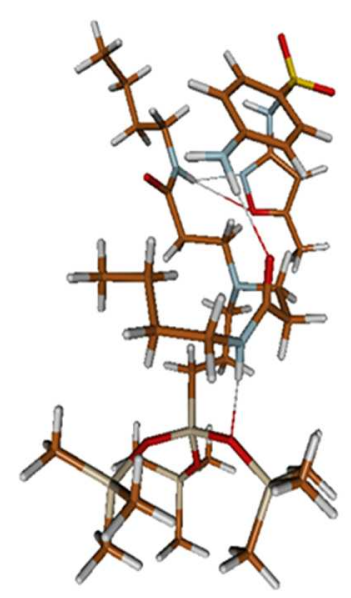

(a)

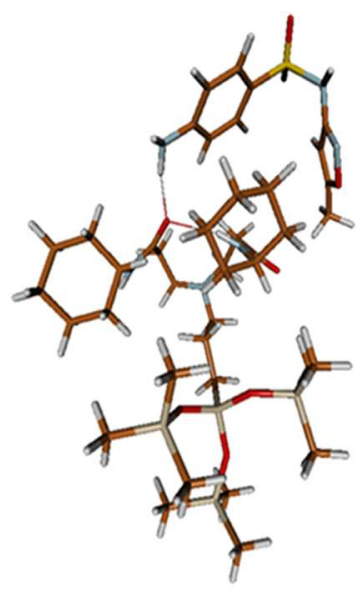

(b)

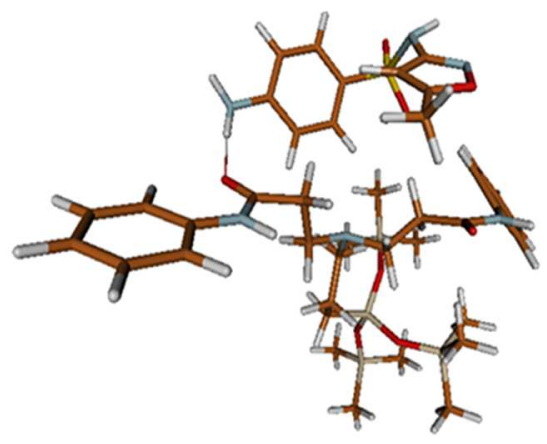

(c)

Figure 5. Most stable orientation of sulfamethoxazole: (a) butylamide, (b) cyclohexylamide, and (c) phenylamide and the functionalized silica fragment. 
Table 4. Largest and average adsorption energies of the sulfamethoxazole molecule on the three types of functionalized silica fragments.

\begin{tabular}{lcc}
\hline Substituent & Largest adsorption energy $\left(\mathrm{kcal} \mathrm{mol}^{-1}\right)$ & Average adsorption energy $\left(\mathrm{kcal} \mathrm{mol}^{-1}\right)$ \\
\hline Hexylamide & -21.9 & -18.7 \\
Phenylamde & -24.4 & -22.1 \\
Butylamide & -29.8 & -27.9 \\
\hline
\end{tabular}

in Figure 5(b) and (c). These hydrogen bonds are around $2.0^{\circ} \AA$ for the $\mathrm{O}-\mathrm{H} \cdots \mathrm{H}$ interaction and from 2.1 to $2.3^{\circ} \AA$ for the $\mathrm{N}-\mathrm{H}^{\cdots} \mathrm{H}$ interaction. The large adsorption energies for all three types of substituents indicate that Van der Waals interactions and possibly $\pi$ aromatic interactions have large contributions to the adsorption energies.

\section{Conclusions}

Three modified amide silica solids were synthesized. The solids were used as stationary phases for the separation of sulfonamides by sequential injection chromatography under isocratic conditions. The mixed interaction mechanism allowed the separation of the sulfonamides. The best chromatographic performance was obtained using silica modified with phenylamide in which $\pi-\pi$ interaction is preferential, although hydrophobic interactions and hydrogen bonding may coexist. The SIC system has the advantages of being economic to use because of their low pressures required, lower reagent consumption ,and low cost equipment compared with high performance liquid chromatography.

\section{Acknowledgment}

We gratefully acknowledge the computer time from Dirección General de Computo y de Tecnologías de Información y Comunicación (DGCTIC) at Universidad Nacional Autonoma de Mexico and the Laboratorio de Visualizacion y Computo Paralelo at UAM-Iztapalapa for the access to its computer facilities.

\section{Funding}

The authors wish to thank the CONACYT (project INFR-2014- 227999) and Junta de Castilla y Leon, (project VA171U14).

\section{References}

Aradi, B., B. Hourahine, and T. Frauenheim. 2007. DFTB+, a sparse matrix-based implementation of the DFTB method. The Journal of Physical Chemistry A 111: 5678-84. doi:10.1021/ jp070186p

Aturki, Z., G. D’Orazio, A. Rocco, K. Si-Ahmed, and S. Fanali. 2011. Investigation of polar stationary phases for the separation of sympathomimetic drugs with nano-liquid chromatography in hydrophilic interaction liquid chromatography mode. Analytica Chimica Acta 685: 103-10. doi:10.1016/ j.aca.2010.11.017

Batista, A. D., P. Chocholouš, D. Šatínský, P. Solich, and F. R. P. Rocha. 2015. On-line hyphenation of solid-phase extraction to chromatographic separation of sulfonamides with fused-core columns in sequential injection chromatography. Talanta 133: 142-49. doi:10.1016/j.talanta.2014.07.056

Cai, X., Z. Guo, X. Xue, J. Xu, X. Zhang, and X. Liang. 2012. Two-dimensional liquid chromatography separation of peptides using reversed-phase/weak cation-exchange mixed-mode column. Journal of Chromatography A 1228: 242-49. doi:10.1016/j.chroma.2011.06.042 
Chen, H. C., C. Wu, and K. Y. Wu. 2015. Determination of the maleic acid in rat urine and serum samples by isotope dilution-liquid chromatography-tandem mass spectrometric with on-line solid phase extraction. Talanta 136: 9-14. doi:10.1016/j.talanta.2014.11.021

Chocholouš, P., L. Kosařová., D. Šatínský., H. Sklenářová, and P. Solich. 2011. Enhanced capabilities of separation in sequential injection chromatography-fused-core particle column and its comparison with narrow-bore monolithic column. Talanta 85: 1129-34. doi:10.1016/j.talanta.2011.05.027

Chocholouš, P., P. Solich, and D. Šatínský. 2007. An overview of sequential injection chromatography. Analytica Chimica Acta 600: 129-35. doi:10.1016/j.aca.2007.02.018

Chocholouš, P., J. Vackovà, I. Šràmkovà, D. Šatínský, and P. Solich. 2013. Advantages of core-shell particle columns in sequential injection chromatography for determination of phenolic acids. Talanta 103: 221-27. doi:10.1016/j.talanta.2012.10.036

Churms, S. C. 1996. Recent progress in carbohydrate separation by high-performance liquid chromatography based on hydrophilic interaction. Journal of Chromatography A 720: 75-91. doi:10.1016/0021-9673(95)00306-1

Croes, K., A. Steffens, D. H. Marchand, and L. R. Snyder. 2005. Relevance of $\pi-\pi$ and dipole-dipole interactions for retention on cyano and phenyl columns in reversed-phase liquid chromatography. Journal of Chromatography A 1098: 123-30. doi:10.1016/j.chroma.2005.08.090

Crystallography.net. 2014. Crystallography open database. http://www.crystallography.net/ (accessed 23 November 2015).

Dioumaeva, I. 2013. Determination of sulfonamides residues in milk with agilent captiva ND lipids filtration and LC/MS/MS. Agilent Technologies, Food Testing and Agriculture, Application Note 5991-2230EN.

Elstner, M., D. Poreza, G. Jungnickel, J. Elsner, M. Haugk, T. Frauenheim, S. Suhai, and G. Seifert. 1988. Self-consistent-charge density-functional tight-binding method for simulations of complex materials properties. Physical Review B 58: 7260-68. doi:10.1103/physrevb.58.7260

Fernández, M., M. Miró, H. M. González, and V. Cerdà. 2008. Modulation of mobile phase composition in flow-injection/sequential-injection chromatography exploiting multisyringe flow analysis. Analytical and Bioanalytical Chemistry 391: 817-25. doi:10.1007/s00216-008-1848-8

Food, and Drug Administration, U.S. 1994. Reviewer guidance: Validation of chromatographic methods, Center for Drugs Evaluation and Research (CDER):21-28. Available at http://www. fda.gov/downloads/Drugs/.../Guidances/UCM134409.pdf (Accessed 23 November 2015).

García-Galán, M. J., S. Díaz-Cruz, and D. Barceló. 2013. Multiresidue trace analysis of sulfonamide antibiotics and their metabolites in soils and sewage sludge by pressurized liquid extraction followed by liquid chromatography-electrospray-quadrupole linear ion trap mass spectrometry. Journal of Chromatography A 1275: 32-40. doi:10.1016/j.chroma.2012.12.004

Gaus, M., A. Goez, and M. Elstner. 2013. Parametrization and benchmark of DFTB3 for organic molecules. Journal of Chemical Theory and Computation 9: 338-54. doi:10.1021/ct300849w

Gaus, M., X. Lu, M. Elstner, and Q. Cui. 2014. Parameterization of DFTB3/3OB for sulfur and phosphorus for chemical and biological application. Journal of Chemical Theory and Computation 10: 1518-37. doi:10.1021/ct401002w

Geudtner, G., P. Calaminici, J. Carmona-Espíndola, J. del Campo, V. D. Dominguez-Soria, R. FloresMoreno, G. U. Gamboa, et al. 2012. deMon2k. Wiley Interdisciplinary Reviews: Computational Molecular Science 2: 548-55. doi:10.1002/wcms.98

Gonzales, C. A., and K. M. Usher. 2009. Determination of sulfonamides in milk using solid-phase extraction and liquid chromatography-tandem mass spectrometry. Agilent Technologies, Pharmaceuticals, Application Note 5990-3713EN.

González-San Miguel H. M., M. Fernández, J. M. Estela, and V. Cerdá. 2009. Contribution of multicommuted flow analysis combined with monolithic columns to low-pressure, high-performance chromatography. TrAC Trends in Analytical Chemistry 28: 336-46. doi:10.1016/j.trac.2008.11.014

Gritti, F., and G. Guiochon. 2004. Heterogeneity of the surface energy on unused C18-chromolith adsorbents in reversed-phase liquid chromatography. Journal of Chromatography A 1028: 105-19. doi:10.1016/j.chroma.2003.11.089

Guiochon, G. 2007. Monolithic columns in high-performance liquid chromatography. Journal of Chromatography A 1168: 101-68. doi:10.1016/j.chroma.2007.05.090 
Guo, H., X. Li, and D. D. Frey. 2014. Developed of chromatofocusing techniques employing mixedmode column packing for protein separations. Journal of Chromatography A 1323: 57-65. doi:10.1016/j.chroma.2013.10.090

Hele, W., M. Brandtner, R. Widek, and R. Schuh. 2003. Determination of sulfonamides in animal tissues using cation exchange reversed phase sorbent for samples cleanup and HPLC-DAD for detection. Food Chemistry 83: 601-08. doi:10.1016/s0308-8146(03)00254-1

Ibarra, I. S., J. M. Miranda, J. A. Rodriguez, C. Nebot, and A. Cepeda. 2014. Magnetic solid phase extraction followed by high-performance liquid chromatography for the determination of sulfonamides in milk. Food Chemistry 157: 511-17. doi:10.1016/j.foodchem.2014.02.069

Ibarra, I. S., J. A. Rodríguez, K. Agilar-Arteaga, E. Contreras-López, and E. Barrado. 2013. Sequential injection magneto chromatography determination of non-steroidal anti-inflammatory drugs in pharmaceutical formulations. Analytical Letters 46: 1732-42. doi:10.1080/00032719.2012.755685

Idris, A. M. 2010. An overview of the generations and recent versions of flow injection techniques. Critical Reviews in Analytical Chemistry 40: 150-58. doi:10.1080/10408340903103437

Idris, A. M. 2014. The second five years of sequential injection chromatography: Significant developments in the technology and methodologies. Critical Reviews in Analytical Chemistry 44: 220-32. doi:10.1080/10408347.2013.848778

Infante, C. M. C., R. de PráUrio, and J. C. Masini. 2011. Improving the detectability of sequential injection chromatography (SIC): Determination of triazines by exploiting liquid core waveguide (LCW) detection. Analytical Letters 44: 503-13. doi:10.1080/00032719.2010.500787

Jangbai, W., W. Wongwilai, K. Grudpan, and S. Lapanantnoppakhun. 2012. Sequential injection chromatography as alternative procedure for the determination of some food preservatives. Food Analytical Methods 5: 631-36. doi:10.1007/s12161-011-9276-3

Kirkland, J. J. 2004. Development of some stationary phases for reversed-phase high-performance liquid chromatography. Journal of Chromatography A 1060: 9-21. doi:10.1016/j.chroma.2004.10.057

Kishida, K., and N. Furusawa. 2001. Matrix solid-phase dispersion extraction and high-performance liquid chromatographic determination of residual sulfonamides in chicken. Journal of Chromatography A 937: 49-55. doi:10.1016/s0021-9673(01)01307-3

Koblová, P., H. Sklenářová, P. Chocholouš, M. Polášek, and P. Solich. 2011. Simple automated generation of gradient elution conditions in sequential injection chromatography using monolithic columns. Talanta 84: 1273-77. doi:10.1016/j.talanta.2011.01.029

Köster, A. M., J. U. Reveles, and J. M. del Campo. 2004. Calculation of exchange-correlation potentials with auxiliary function densities. The Journal of Chemical Physics 121: 3417. doi:10.1063/ 1.1771638

Li, J., Y. Li, T. Chen, L. Xu, X. Liu, X. Zhang, and H. Zhang. 2013. Preparation, chromatographic evaluation and comparison between linear peptide- and cyclopeptide-bonded stationary phases. Talanta 109: 152-59. doi:10.1016/j.talanta.2013.02.005

McCalley, D. V. 2010. The challenges of the analysis of basic compounds by high performance liquid chromatography: Some possible approaches for improved separations. Journal of Chromatography A 1217: 858-80. doi:10.1016/j.chroma.2009.11.068

Minakuchi, H., K. Nakanishi, N. Soga, N. Ishizuka, and N. Tanaka. 1997. Effect of skeleton size on the performance of octadecylsilylated continuous porous silica columns in reversed-phase liquid chromatography. Journal of Chromatography A 762: 135-46. doi:10.1016/s0021-9673(96)00944-2

Rimmer, C. A., and L. C. Sander. 2009. Shape selectivity in embedded polar group stationary phases for liquid chromatography. Analytical and Bioanalytical Chemistry 394: 285-91. doi:10.1007/ s00216-009-2649-4

Šatínský, D., P. Solich, P. Chocholouš, and R. Karlíček. 2003. Monolithic columns - A new concept of separation in the sequential injection technique. Analytica Chimica Acta 499: 205-14. doi:10.1016/s0003-2670(03)00625-1

Seifrtová, M., L. Nováková, C. Lino, A. Pena, and P. Solich. 2009. An overview of analytical methodologies for the determination of antibiotics in environmental waters. Analytica Chimica Acta 649: 158-79. doi:10.1016/j.aca.2009.07.031

Snyder, L. R., J. W. Dolan, and P. W. Carr. 2004. The hydrophobic-subtraction model of reversed-phase column selectivity. Journal of Chromatography A 1060: 77-116. doi:10.1016/j.chroma.2004.08.121 
Sun, H., L. Ai, and F. Wang. 2007. Quantitative analysis of sulfonamide residues in natural animal casings by HPLC. Chromatographia. 66: 333-37. doi:10.1365/s10337-007-0329-0

Unger, K. K., R. Skudas, and M. M. Schulte. 2008. Particle packed columns and monolithic columns in high-performance liquid chromatography-comparison and critical appraisal. Journal of Chromatography A 1184: 393-415. doi:10.1016/j.chroma.2007.11.118

Xu, L., R. Peng, X. Guan, W. Tang, X. Liu, and H. Zhang. 2013. Preparation, characterization and application of a new stationary phase containing different kinds of amine groups. Analytical and Bioanalytical Chemistry 405: 8311-18. doi:10.1007/s00216-013-7243-0

Yang, T. C. C., I. L. Yang, and L. J. Liao. 2004. Determination of sulfonamide residues in milk by online microdialysis and HPLC. Journal of Liquid Chromatography \& Related Technologies 27: 501-10. doi:10.1081/jlc-120027621

Zhang, M., J. Chen, A. K. Mallik, H. Qiu, S. Jiang, and H. Ihara. 2014. Preparation and chromatographic evaluation of new branch-type diamide-embedded octadecyl stationary phases with enhanced shape selectivity. Analytica Chimica Acta 833: 48-55. doi:10.1016/j.aca.2014.05.011

Zhao, M., Z. Li, Y. Wu, Y. R. Tang, C. Wang, Z. Zhang, and S. Peng. 2007. Studies on log P, retention time and QSAR of 2-substituted phenylnitronyl nitroxides as free radical scavengers. European Journal of Medicinal Chemistry 42: 955-65. doi:10.1016/j.ejmech.2006.12.027 